\title{
Indicators of Monetary Policy: The View from Implicit Feedback Rules
}

\section{$\boldsymbol{A}$

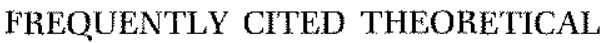
framework for the conduct of monetary policy consists of a policy instrument, an intermediate policy target and a long-run policy objective. The policy instrument is a lever which the central bank can manipulate to achieve its intermediate target. Possible choices for the policy instrument include the quantity of bank reserves, the monetary base (bank reserves plus currency in circulation) or a short-term interest rate. Monetary policymakers aim at a value of the intermediate target variable that will make current monetary policy consistent with a longrun policy objective, such as price stability. ${ }^{1}$ Potential intermediate target variables include nominal gross domestic product (GDP) and monetary aggregates. Ideally, the intermediate target variable is both responsive to policy actions and closely related to inflation in the long run.

In reality, however, the Federal Reserve does not explicitly commit itself to a particular intermediate target variable. Instead, policymakers rely on a number of indicators to evaluate current monetary policy. In the context of a long. run inflation objective, the stance of monetary policy can be interpreted in terms of whether current policy actions are expected to lead to eventual accelerations or decelerations in the inflation rate. Policy indicators are variables (perhaps generated within models) believed to provide reliable information on the stance of current policy. Unfortunately, traditional indicators of monetary policy have given unusually mixed signals in the last several years. ${ }^{2}$ For instance, some economists believe that recent rapid M1 growth portends future increases in inflation, whereas others find signs of further disinflation in slow M2 growth. ${ }^{3}$ To overcome this problem, some researchers have suggested characterizing policy with alternative models of the way the Federal Open Market Committee (FOMC) responds to feedback from potential target variables, such as nominal GDP and M2.4 These models provide a baseline policy, a path of prescribed movements of the policy instru-

\footnotetext{
In this article, I assume that the long-run objective is a low (possibly zero) average intiation rate.

2One way to infer the stance of monetary policy in a world of multiple, possibly conflicting, policy indicators is the narrative approach, first pioneered by Friedman and Schwartz (1963) and re-tnitoduced by Romer and Romer (1989). The narrative approach involves careful study of the historical record, especially summaries of policymaking meetings, to determine the policy intentions of the monetary authority. Many studies using this methodology evaluate economic performance following dates when policy intentions seemed to shift sharply. The retrospective nature of the
}

narrative approach limits its usefulness to policymakers, however, because they often wish to assess whether recent policy actions have been consistent with long-term objectives.

3Ritter's (1993) synopsis of FOMC policy discussions in 1992 refers to the conflicting signals from $\mathrm{M} 1$ and $\mathrm{M} 2$ as a monetary conundrum.

4Motley and Judd (1993), for example, have suggested using monetary rules as a source of a baseline policy for the purposes of policy discussion. 
ment, which we can compare with actual poli$c y$, the actual path of instrument movements. The difference between the actual path and the prescribed path of the policy instrument constitutes a measure of the stance of policy relative to the baseline. In this way, the five models of policy in this article generate five monetary policy indicators that can suggest whether recent policy has changed relative to baselines.

Alternatively, because the FOMC does not explicity identify a particular intermediate target variable, one can view the models of policy examined in this article as investigations into whether the FOMC conducts poticy as if nominal GDP or M2 were the intermediate target variable. Nominal GDP targeting, in particular, has attracted attention in recent years as a way 10 achieve an average inllation rate close to zero in the long run by constraining nominal GDP so it grows at about the rate of the real economy. ${ }^{5}$

This article uses implict feedback rules as models of policy to generate monetary policy indicators. As with all indicators, indicators gener. ated from these models of policy can give conflicting signals, yet the assumptions that he behind each resdback rule are suffictemty testable to allow some scrutiny of the reliability of a given policy indicator. Therefore, I generate and svaluate five policy indicators, based on different sets of assmptions, before reaching some tentative conchsions. "Three of the policy nodels assume that nominal GDP is the intemediate arget variable and two use $\mathrm{M} 2$.

Results rrom two of the nominal GDP targeting ruodels of policy suggest that the FOMC targeted fong-run nominal GDP growth at ather a 4.4 percont annual rate or a 6.5 percent rate from 1983 to 1990 . The former model indicates that monetary base growth has been too rapid since 1990, relative to the model's prescriptions. The latter model, in contrast, indicates that monetary base growth has been too slow since 1990 , relative to that model's prescriptions. The third nominal GDP targeting model implies that the FOMC was largeting nominal GDP growth at a 5.7 percent rate from 1983 to 1990 . According to the third model, monetary policy actions accommodated lower nominal GDP growth in the recession of 1990-91 without providing clear-cut evidence of a change in the long-run inflation objective between the 1980 s and 1990s.

The results also suggest that monetary policy in the early 1990 s has generally been consistent with the wo models of M2 targeting studied here. In these models, the ratio between $M 2$ and the monetary base must be predieted one quarter ahead. Ifind that the recent slow growth in $\mathrm{M} 2$, relative to the FOMC target ranges, could be attributable to prediction errors resulting from a breakdown in the relationship between the monetary base and M2. In other words, it is difficult in the current financial environment to forecast the effects of policy actions on M2. Furthermore, forecasting results suggest that the breakdown in the relationship between M2 and the monetary base is more severe than the much-discussed breakdown in $\mathrm{M} 2$ velocity.

\section{FEEDBACK RULES}

For the purposes of this paper, a feedback rule is a pre-commitment on the part of the monetary authority as to how it will bse policy levers in response to developments in its intermediate target variable. Under a feedback rule, the Fed would monitor the target variable and adiust th instruments in response, but these conditional responses would be pre-specified. One well-known reedback rule proposed by McCallum (1987) uses the adjusted monetary base as a policy instrument to farget nominal GDP. All three models of nominal GDP targeting in this articte share the assumption in McCallum's rule that the long.run inflation objective remains constant." If the inflation objective were to change, the nominal GDP targeting feedback rales would change also. The adjusted monetary base serves as a convenient measure of the use of policy levers, because Federal Reserve policy actions are quantitatively summarized in the adjusted base: changes in nonborrowed reserves, borrowed reserves and reserve requirements. McCallum's rule serves as one model of de facto wed policy, whereby the Fed

\footnotetext{
5 Bradley and Janssen (1989) stummarize the rationale for nominat GNP targeting.

The nominal GDP targeting models target a constant rate of long-run nominal GDP growth, as will be shown below. Assuming that the long-term growh rate for the real economy is consiant and policy-irvalian, the long-term inflation objective will be constan.
} 
is assumed to target a growth path for nominal GDP.

If the FOMC were targeting $\mathrm{M} 2$, rather than nominal GDP, how might such a policy be implemented? As a second model of de facto Fed policy, $I$ assume that the Fed gears its policy (again summarized by the changes in the adjusted monetary base) to target $\mathrm{M} 2$ at the midpoint of the M2 cone, which the Fed reports every year in its Monetary Policy Objectives publication. ${ }^{7}$ if the announced cone were the policy objective such that the Fed limited itself to policies in. tended to steer M2 toward the midpoint, then we could consider M2 targeting to be a shortrun feedback rule.

Like McCallum's nominal GDP targeting rule, M2 targeting models generate implied policies in terms of base growth. ${ }^{8}$ Recent base growth can then be characterized as consistent or inconsistent with the model-implied policies. Unlike the nominal GDP targeting models of policy, however, the two M2 feedback rules do not necessarily assume that the long-run inflation objective remains constant. If one accepts the proposition of Hallman, Porter and Small (1991) that the long-run velocity of $\mathrm{M} 2$ is constant, then a permanent change in the target rate of $\mathrm{M} 2$ growth implies a permanent change in the target rate of nominal GDP growth and in the long-run inflation objective.

\section{The Role of Forecasts in Feedback Rules}

Models in which $\mathrm{M} 2$ is the target variable require forecasts of the ratio between $\mathrm{M} 2$ and the monetary base to identify the rate of base growth believed sufficient to put it at the midpoint of the FOMC's target range. If the FOMC were targeting nominal GDP with McCallum's rule, on the other hand, it would require forecasts of the velocity of the monetary base. One way to make these forecasts is to use average velocity growth over the past four years as a forecast of the next quarter's velocity growth. ${ }^{9}$ Moving-average (MA) forecasts gradually incorporate shifts in the trend of velocity growth, yet assume that many changes in velocity growth are transitory. As an alternative, Dueker (1993) generates forecasts of base velocity with a timevarying coefficient (TVC) regression model with heteroscedastic errors. An advantage of the TVC regression model, relative to a four year moving average, is that the forecasting information set inchudes not only past values of the dependent variable, but also a host of explanatory variables. ${ }^{10}$ The advantage of allowing for time-varying coefficients, relative to fixed-coefficient models, is that they can adapt to structural breaks in the relationships between the dependent and explanatory variables. This article includes comparisons of models of monetary policy that use both the moving-average forecast method and the TVC forecast method.

\section{A Forecast Comparison for Base Velocity}

Because forecasts play a large role in the models of monetary policy presented here, figure 1 illustrates the forecast performance of the time-varying coefficient model for quarterly base velocity growth. ${ }^{11}$ In general, the TVC model forecasts base velocity well until 1991, after which the model has overpredicted basevelocity growth. As a comparison, figure 1 includes four-year, moving-average forecasts and shows that the MA forecasts display much less variation than forecasts from the TVC model. This difference suggests that the choice of forecasting models can have a large impact on nominal GDP targeting models. It is also worth noting that the mean-squared forecast error for the moving average is more than three times that of the TVC model. Nevertheless, figure 1 shows that since 1991 both forecast methods have been overpredicting base velocity growth by similar magnitudes.

\footnotetext{
11The appendix discusses the specification of the forecasting model.
}

7 Congress, in the Humphrey-Hawkins Act of 1978, requires the Federal Reserve to report any targets it sets for monetary aggregates, although such targets may not necessarily be a primary objectve of monetary poiicy.

${ }^{8}$ There are, of course, many other possible targets, but 1 restrict attention to these two interesting cases.

\$McCallum (1987) uses four-year, moving-average forecasts.

${ }^{10}$ The explanatory variables used were lagged changes in the three-month Treasury bill rate and lagged growth in the monetary base. Future work might include a long-term bond rate as well. 
Figure 1

Quarterly Growth in Base Velocity, Forecasted Growth
from TVC Model and Four-Year, Moving-Average Forecasts

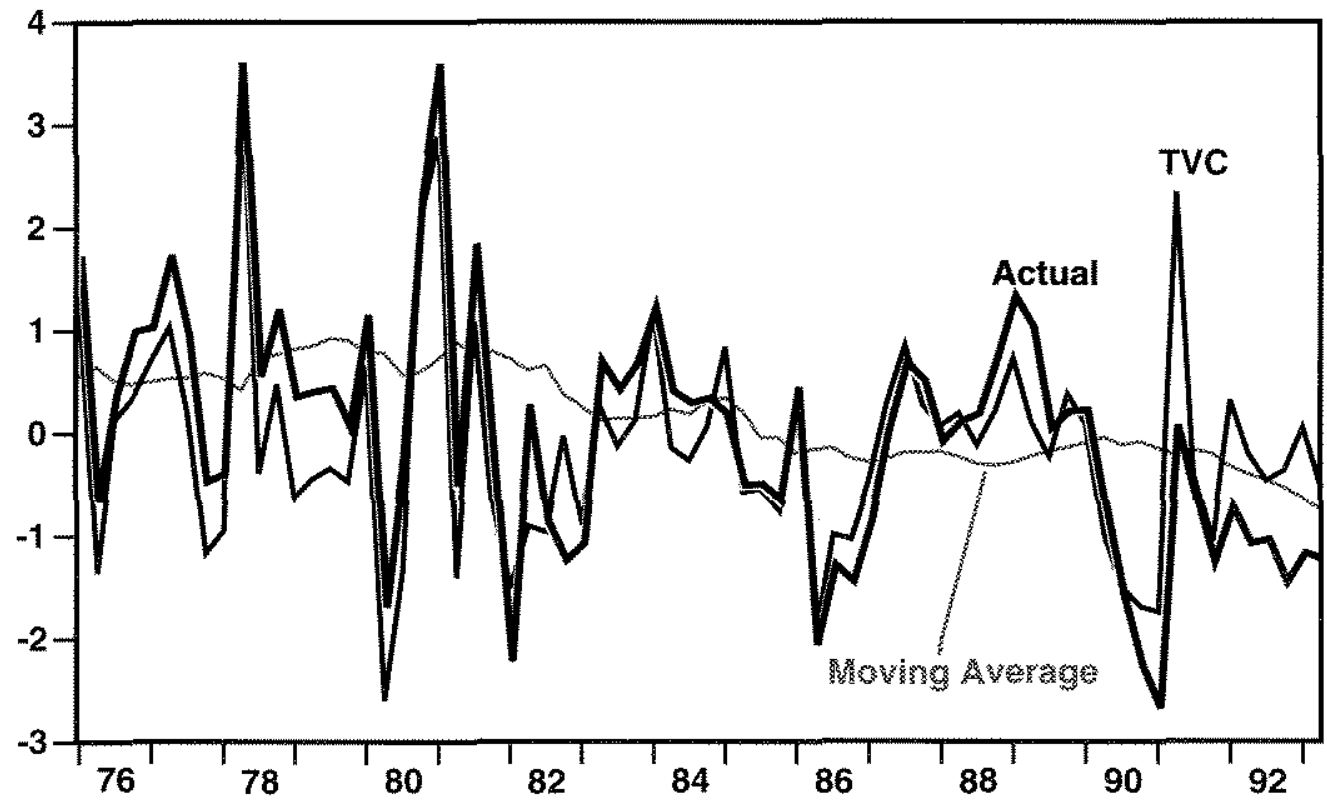

GHARACTERIZING MONETARY POLICY FROM 1983-1990 WITH NOMINAL GDP FEEDBAGK RULES

\section{Fixed GDP Target Paths}

McCallum-type monetary rules offer models of nominal GDP targeting policies: ${ }^{22}$

(1) $\Delta \ln M B_{t}=\lambda_{0}-\Delta \ln V_{t i+1}+\lambda_{i}(\ln G \hat{D} P-\ln G D P)_{t-1}$

$$
\Delta \ln G \hat{D} P_{t}=\lambda_{0} \forall t
$$

where $M B$ is the monetary base, $\Delta \ln V_{t / t-1}$ is the forecasted value of base velocity growth, and GDP is the target level of nominal GDP. The parameter $\lambda_{0}$ equals the growth rate of target nominal GDP, whereas $\lambda$, specifies how much to raise base growth in the coming quarter in response to a given percentage gap between target and actual nominal GDP. So, in characteriz- ing monetary policy with a monetary rule such as equation (1), one must choose a velocity forecasting model, specify in which quarter actual and target nominal GDP were equal, and choose values for $\lambda_{i}$ and $\lambda_{r}$. This section compares models of monetary base growth stemming from two versions of the nominal GDP feedback rule found in equation (1): One model uses a time-varying coefficient model to generate forecasts of base velocity growth and the other uses four-year, moving-average forecasts. The former will be called the TVC GDP model and the latter the MA GDP model. For each model, parameter values for $\lambda_{0}$ and $\lambda_{1}$ are chosen to minimize the mean-squared error between actual base growth and the model-implied base growth from the third quarter of 1983 to the first quarter of 1990. To examine whether implicit monetary policy feedback rules benchmarked in the $1980 \mathrm{~s}$ can explain monetary policy actions to the present, post-1990 data are left as out-of-sample observations.

${ }^{12 S e e ~ M c C a l l u m ~(1987) ~ f o r ~ d e t a i l s ~ o f ~ h i s ~ p r o p o s e d ~ r u l e . ~}$ 
Figure 2

\section{Quarterly Growth in Monetary Base and Growth Implied by a GDP Targeting Rule with TVC Forecasts of Base Velocity}

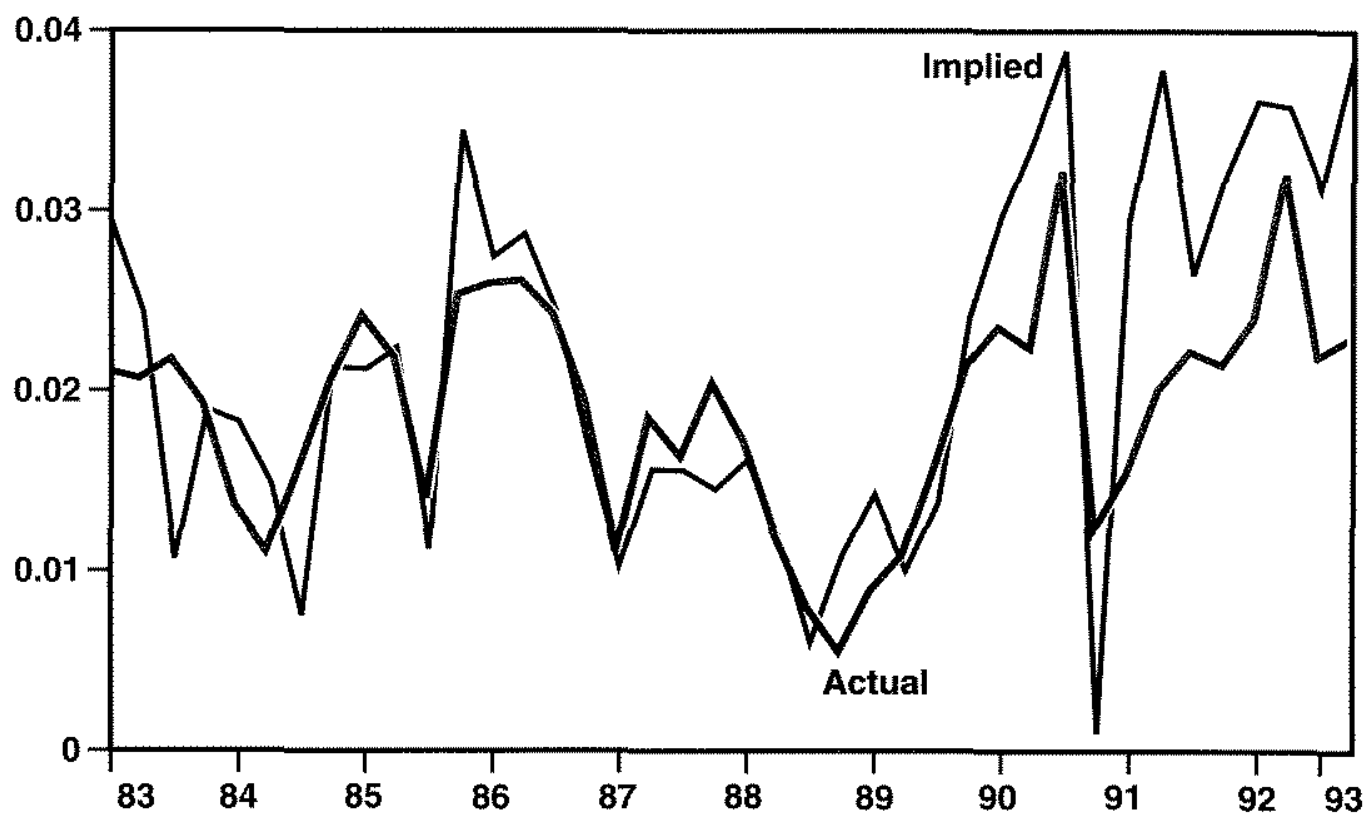

\section{Results for TVC GDP Model}

For the TVC GDP model, the minimum meansquared error over this time period is achieved when $\lambda_{v}=0.0159, \lambda_{1}=0.275$ and $G D P=G \hat{D} P$ in the first quarter of $1985 . .^{13} \mathrm{~A}$ value of 0.0159 for $\lambda_{a}$ corresponds to a 6.5 percent annual growth tate for target nominal GDP. Figure 2 plots the base growth implied by the TVC GDP model and actual base growth. The TVC GDP model explains the in-sample, pre-1990 data fairly well but, since 1990, base growth has been below that implied by the model. Figure 3 plots nominal GDP and the target level implied by the TVC GDP model. It shows a slowing in nominal GDP growth since mid-1990. The growing gap between the rule-implied target and actual

13Because of the feedback rule uses the log-level of nominal GDP, discrepancies between firstrelease nominal GDP data and revised data will not have a large effect on implied base growth. Consider, for example, a revision in annual nominal GDP growth of 2 percent. This relativey large revision would change the log-level of nominal GDP by about one-half of 1 percent for that quarter. When muttiplied by $\lambda_{1}=0.275$, the revision would catse a change in the implied growth rate of the monetary base equal to 0.00136 . Given the variation of implied base growth in nominal GDP accounts for the high rates of base growth implied by the model from 1991 to the present. The feedback rule in the TVC GDP model would call for an increase of 1.1 percent in the annualized growth rate of the monetary base for every percentage point gap between target and actual nominal GDP. Because actual base growth has not been increased according to this formula in the 1990s, the results are consistent with the view that the FOMC is implicitly targeting a lower path for nominal GDP. Moreover, the fact that the TVC forecasts have been overpredicting base growth in the 1990s (as shown in figure 1) only buttresses this find. ing because, without the forecast errors, the TVC GDP model would have implied even faster base growth since 1991 .

figure 3 , the effect of using revised data is not of a consequential magnitude. 
Figure 3

\section{Logarithm of Nominal GDP and Target Level Implied by a Nominal GDP Target Rule that Uses TVC Forecasts}

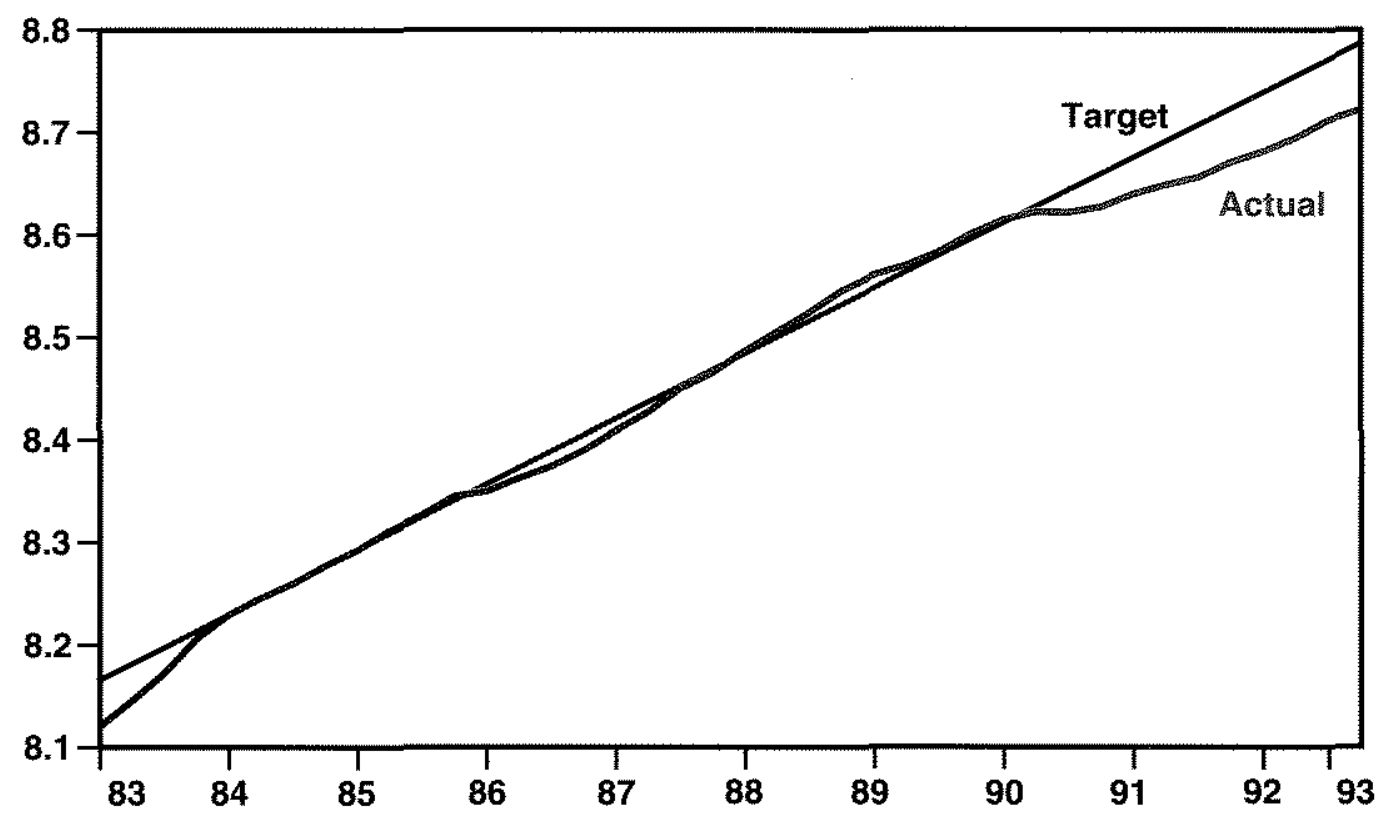

\section{Results for MA GDP ModeI}

It is also possible to characterize policy with a model of nominal GDP targeting that uses 16 . quarter, moving-average forecasts of base velocity, as suggested by MoCallum (1987), in what we call the MA GDP model:

$$
\text { (2) } \begin{aligned}
\Delta \ln M B_{t}= & \lambda_{o}-\frac{1}{16}\left(\ln V_{t-1}-\ln V_{t-17}\right) \\
& +\lambda_{i}(\ln G \hat{D} P-\ln G D P)_{t-1} \\
& \Delta \ln G \hat{D} P_{t}=\lambda_{o} \forall t_{t}
\end{aligned}
$$

where $V$ stands for the velocity of the monetary base. The MA GDP model explains base growth in the middle to late 1980 s with a target path for nominal GDP that is very different from that of the TVC GDP model. The nominal GDP feedback rule with moving-average forecasts ex. plains base growth from the third quarter of 1983 to the first quarter of 1990 with minimum mean-squared error when $\lambda_{0}=0.0108$, which corresponds with a 4.4 percent annual growth rate for target nominal GDP, $\lambda_{T}=0.0945$ and $G D P=G \hat{D} P$ in the first quarter of $1989 .{ }^{14}$

The results suggest that inferences regarding a target path for nominal GDP are sensitive to the method of forecasting base velocity growth, even though the forecasted values from the two methods have nearly identical means. Figure 4 plots nominal GDP and the target level defined by the MA GDP model. This model suggests that the long-term nominal GDP target growth rate was a relatively low 4.4 percent annual rate in the 1980s. The MA GDP model would explain rapid nominal GDP growth in the middle to late 1980 s by indicating that nominal GDP stood well below the target level following the 1981-82 recession. In this case, nominal GDP could grow at about a 7 percent rate without exceeding the target level until 1989. Moreover, nominal GDP has remained only slightly above the implied

${ }_{14}$ The optimal values of the feedback parameters, $\lambda_{7}=0.275$ for the model that uses forecasts from the TVC model and $A_{1}=0.095$ for the model that uses moving-average forecasts are close to the values that worked well in simulations of the two rules in Dueker (1993), 0.25 and 0.10 , respectively. 
Figure 4

\section{Logarithm of Nominal GDP and Target Level as Defined by a Nominal GDP Targeting Model That Uses Moving- Average Forecasts}

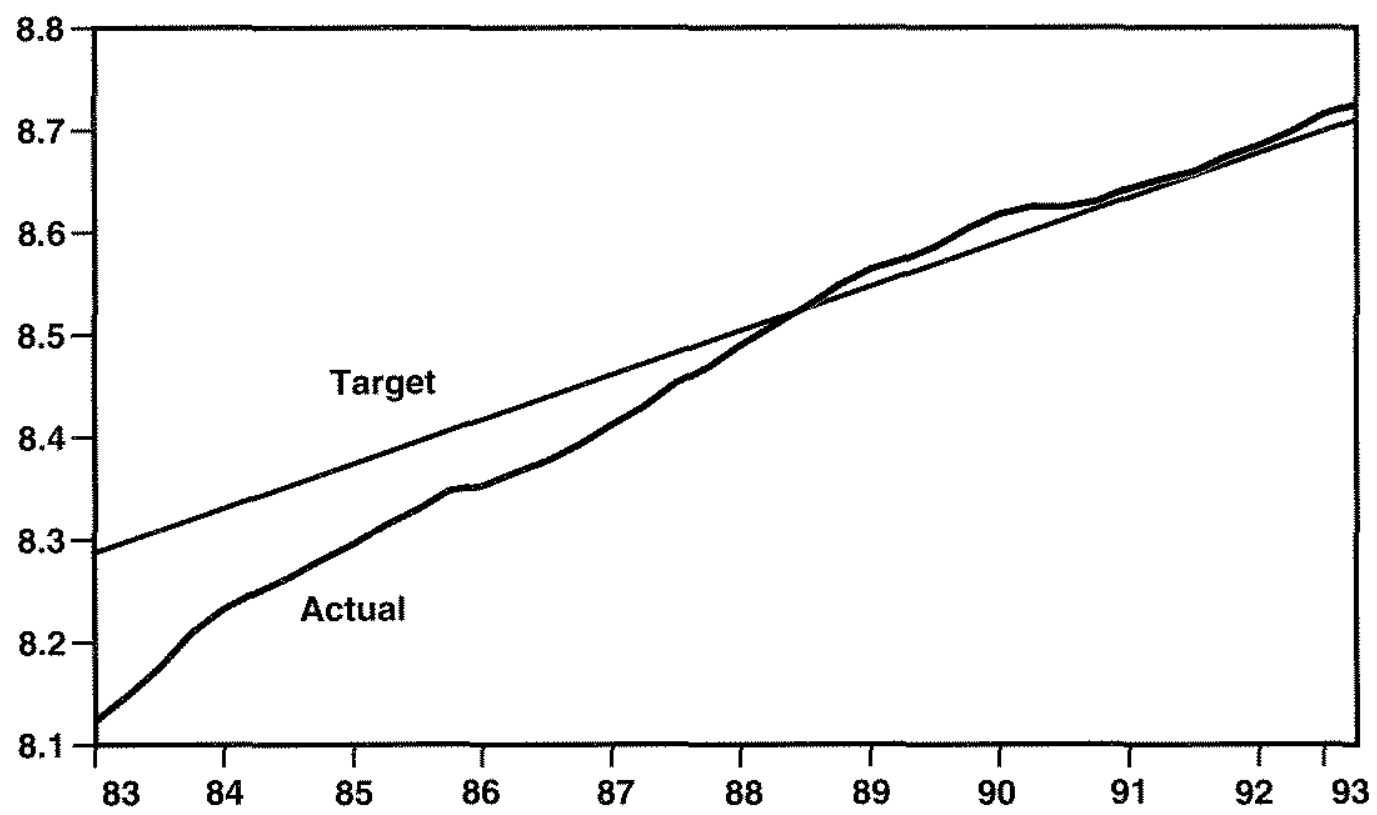

target level in the post-1990, out-of-sample observations.

Figure 5 shows that the MA GDP model called for much less variation in base growth than actually took place. The smoothness in the implied base growth rates owes to the four-year, moving-average forecasts of base velocity. Smoothness, however, should not be confused with constancy. The rate of base growth implied by the MA GDP model decreases significantly between 1984 and 1990, as the gap between target and actual nominal GDP narrowed. In the post-1990, out-of-sample period, base growth has consistently been above that implied by the MA GDP rule. Nevertheless, because the moving-average forecasts have generally overpredicted base velocity growth since 1990 , as shown in figure 2 , the model would have implied faster base growth and, therefore, would have been closer to actual base growth, without the forecast errors.

Given the striking differences in the target paths for nominal GDP implied by the TVC and MA GDP models, it is not supprising that oppos- ing conclusions emerge concerning whether base growth in the early 1990s has been too high or too low to be consistent with the two models. Actual base growth since 1990 has generally been lower than that implied by the TVC GDP model and too high to be consistent with the MA GDP model, despite the fact that both models have experienced similar forecast errors since 1991.

\section{Rebased GDP Target Paths}

Both of the above models, however, might be overly influenced by the assumption that the FOMC has relentlessly pursued a constant growth path for nominal GDP without making allowances for past mistakes. McCallum (1993) has proposed an alternative to targeting a time-invariant, constant growth path for nominal GDP by making this period's nominal GDP target level a weighted average of last period's target and actual levels:

(3) $\ln G \hat{D} P_{t}=\lambda_{0}+\delta \ln G \hat{D} P_{t-1}+(1-\delta) \ln G D P_{t-1}$

Setting $\delta=1$ recovers the time-invariant, con- 
Figure 5

\section{Quarterly Growth in Monetary Base and Growth Implied by a Model of Nominal GDP Targeting That Uses Moving- Average Forecasts of Base Velocity}

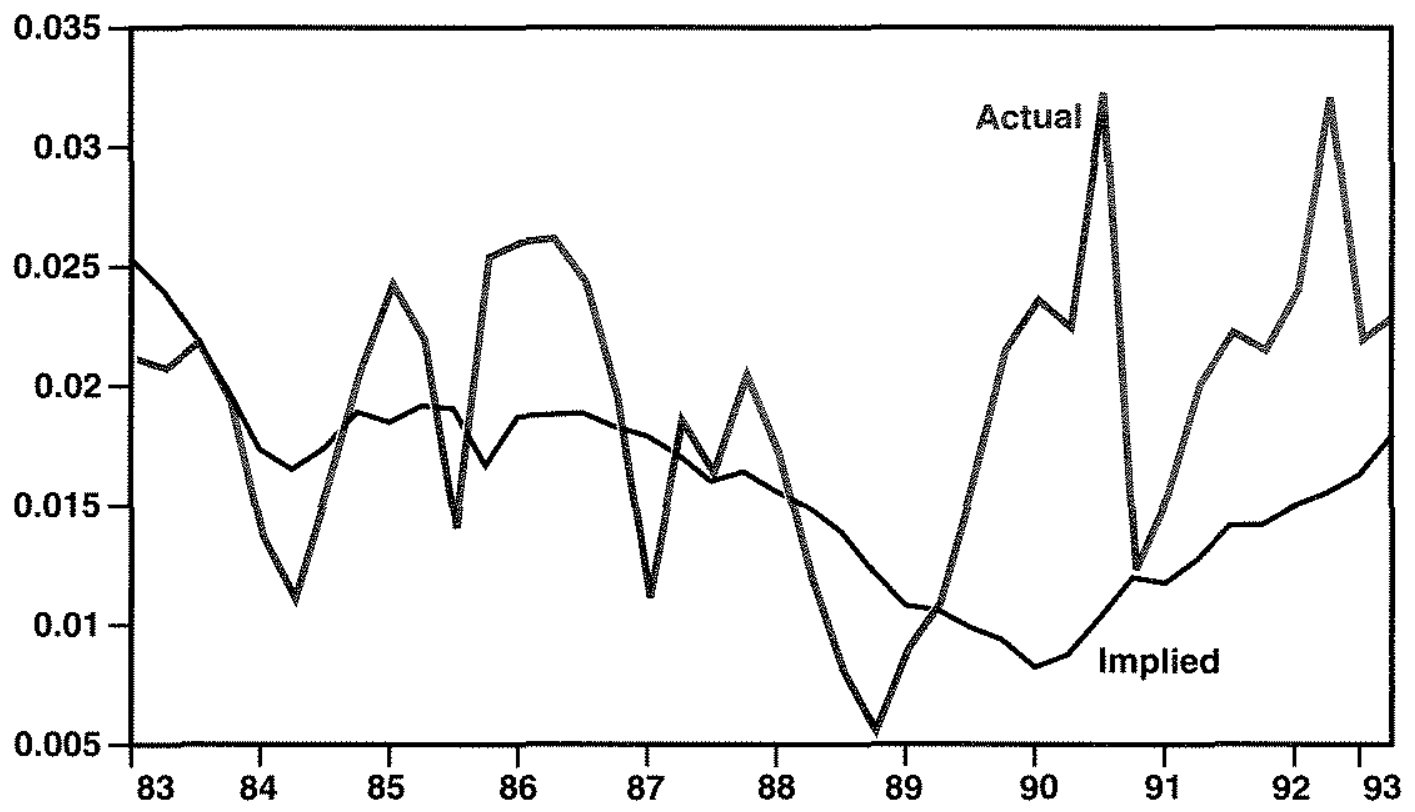

stant growth target path used in the TVC and MA GDP models, whereas setting $d=0$ means that, quarter after quarter, the target is to achieve nominal GDP growth equal to $\lambda_{0}$ and no attempt is made to correct for past mistakes, ${ }^{15}$ Feldstein and Stock (1993), for example, use a nominal GDP targeting model that sets $\delta=0$. A value of $\delta$ between zero and one allows intermediate cases between targeting a constant growth rate period by period $(\delta=0)$ and targeting a fixed, pre-specified path for nominal GDP $(\delta=1)$. If $\delta=1$, past mistakes are always corrected and never accommodated. If $\delta=0$, past mistakes are never corrected and immediately accommodated. If $\delta$ is between zero and one, past mistakes are gradually accommodated.

To relax the assumption that all past mistakes will be corrected later, base growth is modeled using a nominal GDP feedback rule with target nominal GDP determined by equation (3). This model, which uses the time-varying coefficient model to forecast base velocity, is called the rebased target GDP model. The parameter values that minimize the mean-squared error between actual and model-implied base growth from the third quarter of 1983 to the first quarter of 1990 are $\lambda_{\theta}=0.0140$, which corresponds with a 5.7 percent annual rate for target nominal GDP growth, $\lambda_{1}=1.043, \delta=.698$ and $G D P=G \hat{D} P$ in the first quarter of 1989. Gradually rebasing the nominal GDP target, as indicated by $\delta<1$, prevents nominal GDP from deviating far from its target level, and thereby permits a larger value for the feedback parameter, $\lambda_{i}$. Figure 6 plots the actual and target levels of nominal GDP, where the target level is defined by the rebased target GDP model. The chart shows that rebasing the nominal GDP target gradually accommodates past periods of nominal GDP growth

15Targeting a fixed, pre-specified path for nominal GDP as opposed to a constant growth rate, period by period, is analogous to targeting the price level as opposed to targeting the inftation rate at zero each period. In each case, the choice hinges on whether to accommodate one-time shitts in the level. 
Figure 6

\section{Logarithm of Nominal GDP and Target Level as Defined by a Nominal GDP Targeting Rule That Rebases the Target}

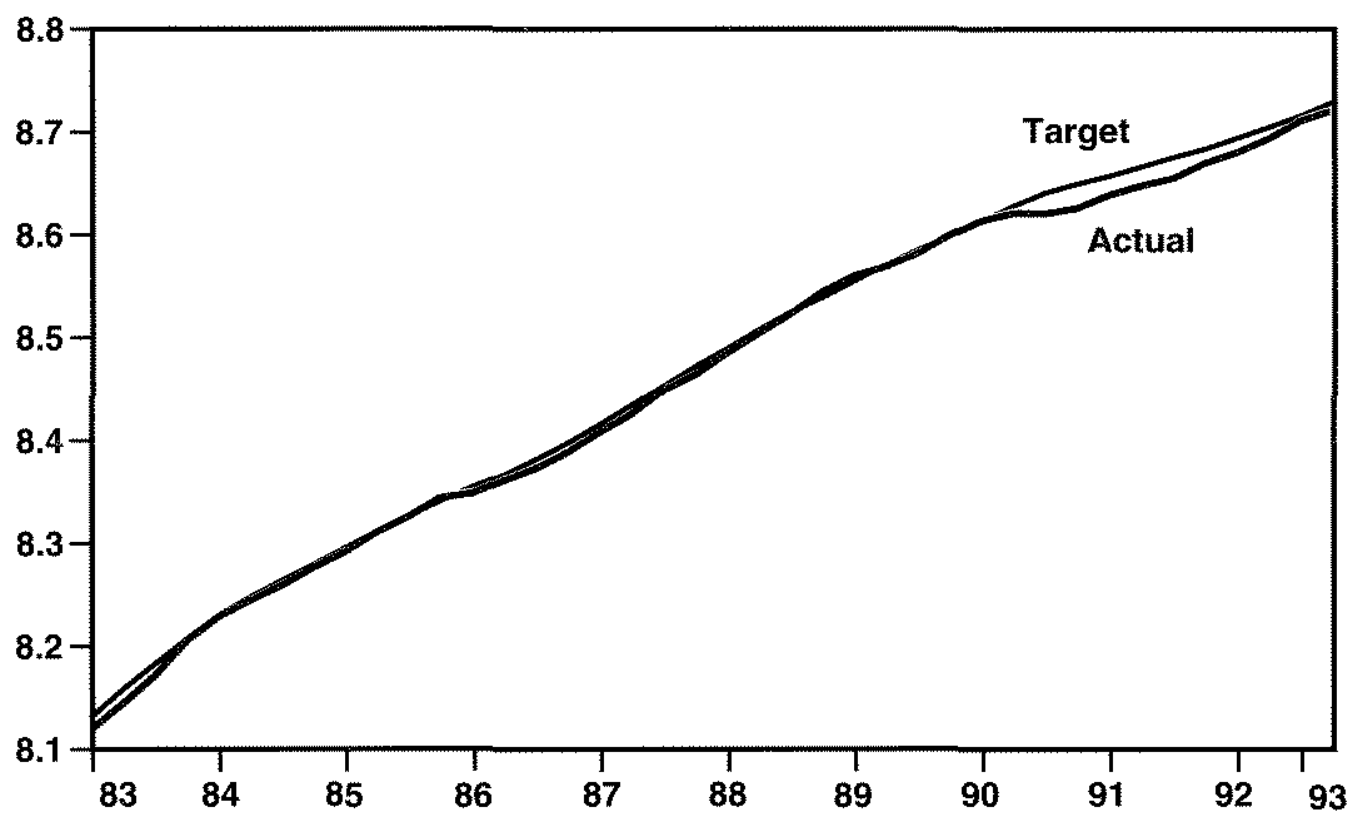

above or below the expected 5.7 percent rate. The 1990-91 recession, for example, brought a slowdown in nominal GDP growth that tem. porarily created a positive gap between target and actual nominal GDP. By early 1993, the gap had been bridged, in part due to rebasing the target, as evidenced by a shallowing in the slope of the target path for nominal GDP since 1990. Figure 7 shows the actual and model-implied monetary base growth rates for the rebased target GDP model. The model explains base growth quite well until mid-1990, which is the beginning of the out-of-sample period and also the onset of the recession. During the recession and recovery, actual base growth remained below that implied by the rebased target GDP model until mid-1992. As figure 1 shows, however, the TVC forecasts of base velocity have tended to overpredict base velocity growth in the early 1990s, so the rebased target model, like the other nominal GDP targeting models, would have implied even higher base growth without the forecast errors.

The rebased target GDP model has a lower in-sample (1983-90) mean-squared error than either the TVC GDP on MA GDP model. Table 1 contains summary measures of the bias and mean-squared error between actual and modelimplied base growth, both in- and out-of-sample, for each of the three GDP targeting models. The TVC and MA GDP models explain base growth with nearly identical success, which is somewhat surprising considering the dissimilarity of their implied target paths for nominal GDP. They also do slightly better than the rebased target GDP model (in terms of mean-squared er. ror) in explaining base growth since 1990.

In sum, this exercise illustrates the difficulty of determining the Fed's long-run inflation objective from models of nominal GDP targeting. The results for the TVC GDP and MA GDP models show that alternative models of monetary policy can explain base growth with fairly similar success, while implying dramatically different target paths for nominal GDP.

Moreover, the divergence in results for the TVC and MA GDP models does not appear to have a simple intuitive explanation. It appears that 


\section{Figure 7 \\ Quarterly Growth in Monetary Base and Growth implied by a Nominal GDP Targeting Rule That Rebases the Target}

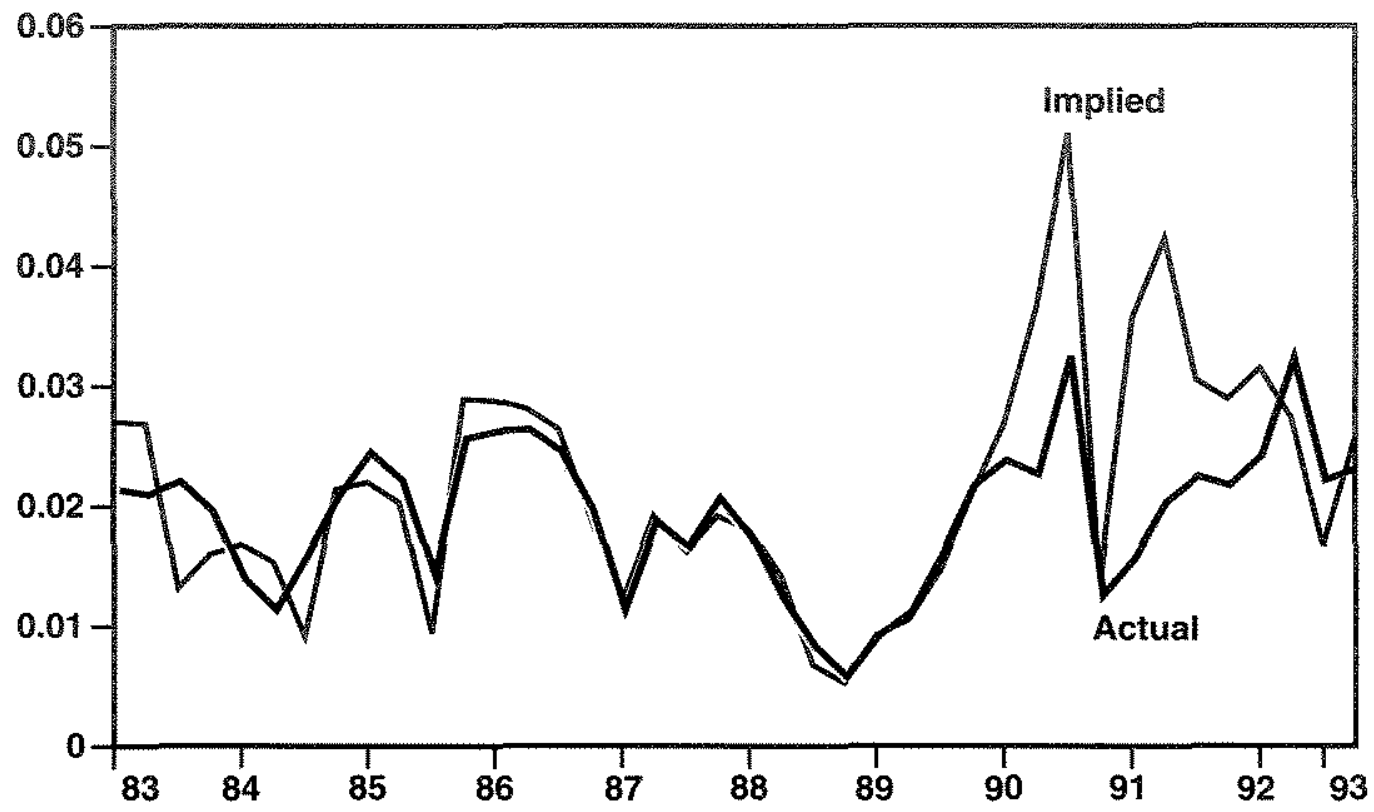

more time and data are needed to determine which of these two models best describes monetary policy objectives. In time we can observe whether nominal GDP more closely adheres to the MA GDP model's 4.4 percent growth path or the TVC GDP model's 6.5 percent growth path. Stated in terms of inflation rates, the MA GDP model suggests that the average inflation rate will be about 2 percent, allowing for roughly 2.5 percent growth in potential real GDP. The TVC GDP model, on the other hand, predicts a higher average inflation rate of about 4 percent.

Fortunately, however, we are not forced to draw inferences from only these two models, because the rebased target GDP model appears to dominate both in terms of in-sample, meansquared error in explaining base growth. From the rebased target GDP model, which has a $\mathbf{5 . 7}$ percent target rate of nominal GDP growth, we can infer that the Fed's long-run inflation objective in the middle-to-late 1980 s was approximately 3 percent. Furthermore, after allowing for the slowdown in nominal GDP growth surrounding the recession of 1990-91, the rebased target GDP model does not forcefully indicate a change in the long-run inflation objective between the $1980 \mathrm{~s}$ and $1990 \mathrm{~s}$. In this context, a persistent and widening gap between target and actual nominal GDP would suggest a change in the long-run inflation objective, and no such gap develops for the rebased target GDP model.

\section{GHARACTERIZING MONETARY POLICY FROM 1983-90 WITH AN M2 TARGETING FEEDBACK RULE}

As with models of nominal GDP targeting, I construct models of $\mathrm{M} 2$ targeting that employ both moving-average forecasts and forecasts from a time-varying coefficient model. The model that uses a time-varying coefficient forecasting method for the M2/base ratio will be the TVC M2 model, and the model that uses a moving-average method will be the MA M2 model. The assumed short-run feedback rule behind these two models is that the Fed sets base growth to attempt to put M2 at the midpoint of the announced $\mathrm{M} 2$ target range, given a forecast of the M2/base ratio. Because $\mathrm{M} 2$ has generally lagged below the midpoint (and often 


\section{Table 1}

\section{Model Comparison}

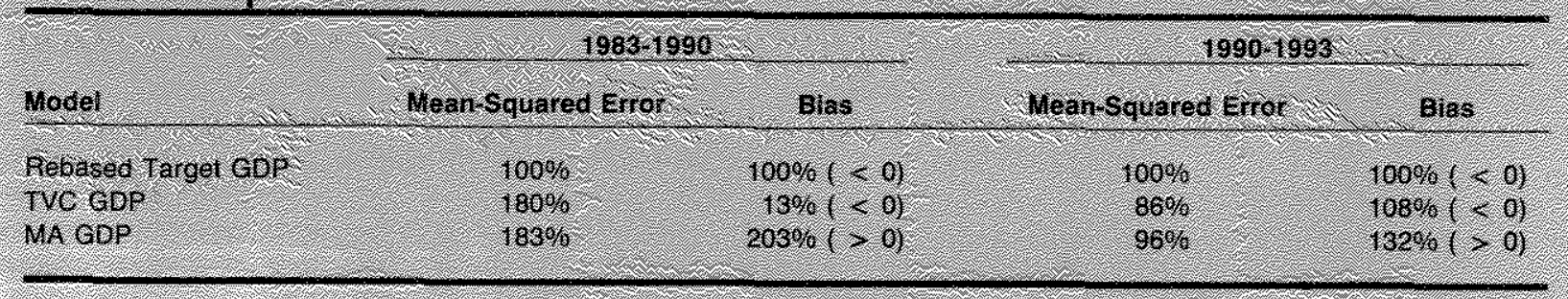

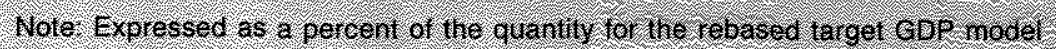

below the bottom) of its target ranges in the $1990 \mathrm{~s}$, one objective of this exercise is to learn whether the shortfall can be attributed to a problem in predicting the M2/base ratio, or to a decision on the part of policymakers to pursue other objectives that preclude placing $\mathrm{M} 2$ at the midpoint of the target range.

Figure 8 plots actual base growth and base growth implied by the TVC M2 model. The chart shows that differences between base growth and base growth implied by the model of M2 targeting are not noticeably larger in the 1990 s than in the 1980 s. Figure 9 provides similar results for the MA M2 model. Actual base growth has been fairly consistent with the base growth implied by either M2 targeting model. Nevertheless, we know that M2 has been near the bottom of or below its target range in the 1990 s. Figure 10 plots M2's position relative to the midpoint of its target range to illustrate that M2 has consistently been below the midpoint of the target range since 1991. The substantial gap between actual $\mathrm{M} 2$ and the midpoint of its target range stands at odds with the relatively small differences between actual base growth and base growth implied by the TVC M2 and MA M2 models in figures 8 and 9 . The two forecast-based models of base growth have falsely been suggesting that base growth has been high enough to place M2 about the midpoint of its target range. Evidently, forecast errors are distorting these models of M2 targeting. To verify that forecasting models are breaking down, figure 11 shows actual growth in the M2/base ratio and growth forecasted by a timevarying coefficient model. Figure 11 shows that the forecasting model has been overpredicting the $\mathrm{M} 2 /$ base ratio since 1991 by a large amount, relative to pre-1991 prediction errors. Conse- quently, the TVC M2 model since 1991 has been implying rates of base growth that have subsequently proved insufficient to hit the midpoint of the M2 target range.

The relationship between the monetary base and M2 has apparently undergone such rapid change that even a time varying coefficient model has not kept pace. What has happened to the relationship between the monetary base and M2? The principal factor behind recent unanticipated decreases in the $\mathrm{M} 2$ /base ratio may be the shrinking spread between rates paid on small time and other checkable deposits. Liquid, interest-bearing checkable deposits have become more attractive as the spread has decreased. By putting funds from maturing small time deposits into other checkable deposits, savers force banks to hold more reserves for a given level of $\mathrm{M} 2-$ hence, decreases in the $\mathrm{M} 2 /$ base ratio. Empirical models have overpredicted the $\mathrm{M} 2 /$ base ratio, largely because forecasting models had not foreseen the magnitude of the substitution out of time deposits into other checkable deposits.

Regulatory actions have also helped facilitate the flow of funds out of small time deposits in ways that statistical forecasting models could not have anticipated. For example, in the aftermath of the savings-and-loan crisis, the Resolution Trust Corporation allowed purchasers of failed thrifts to terminate small time deposits, a key M2 component, at the time of takeover, and allowed depositors at failed thrifts to withdraw their money before maturity from small time deposits without penalty. Together, these changes have contributed to lower $\mathrm{M} 2 / \mathrm{base}$ ratios than forecasting models had foreseen.

It is also interesting to note that the break- 
Figure 8

Quarterly Growth in Monetary Base and Growth Implied by Midpoint of M2 Target Range and TVC Model Forecast of M2/Base Ratio

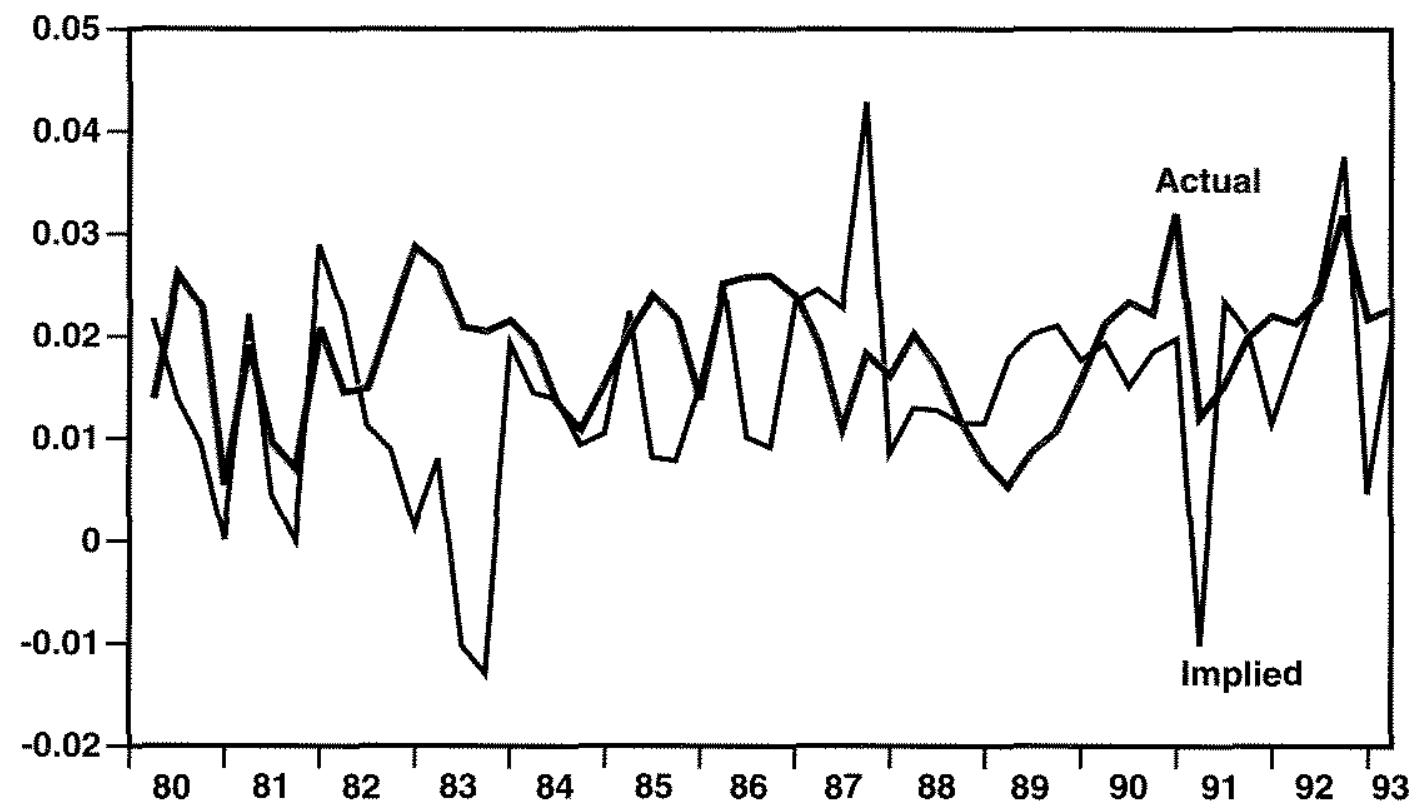

Figure 9

Quarterly Growth in Monetary Base and Growth Implied by Midpoint of M2 Target Range and Moving-Average Forecasts of M2/Base Ratio

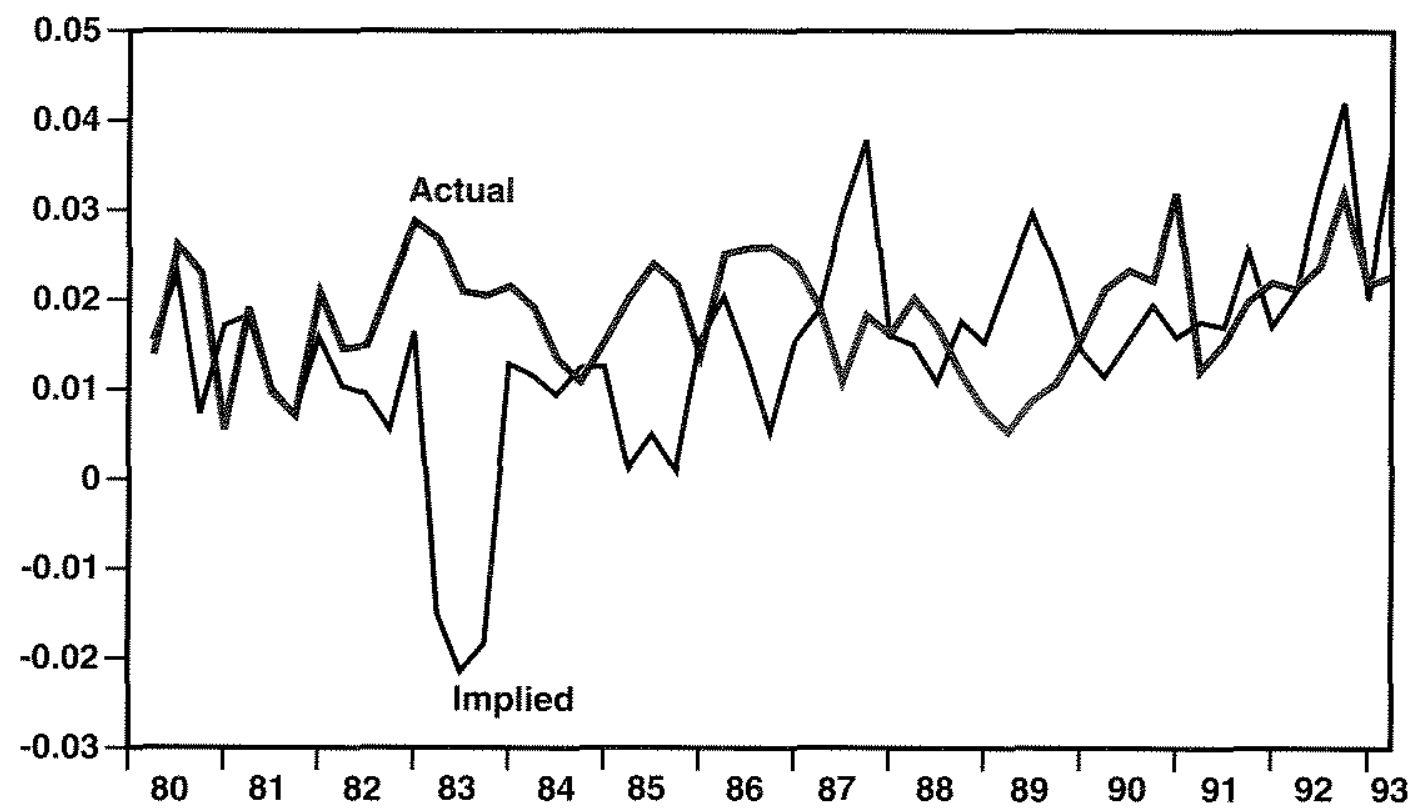


Figure 10

Actual M2 and Midpoint of FOMC Target Range

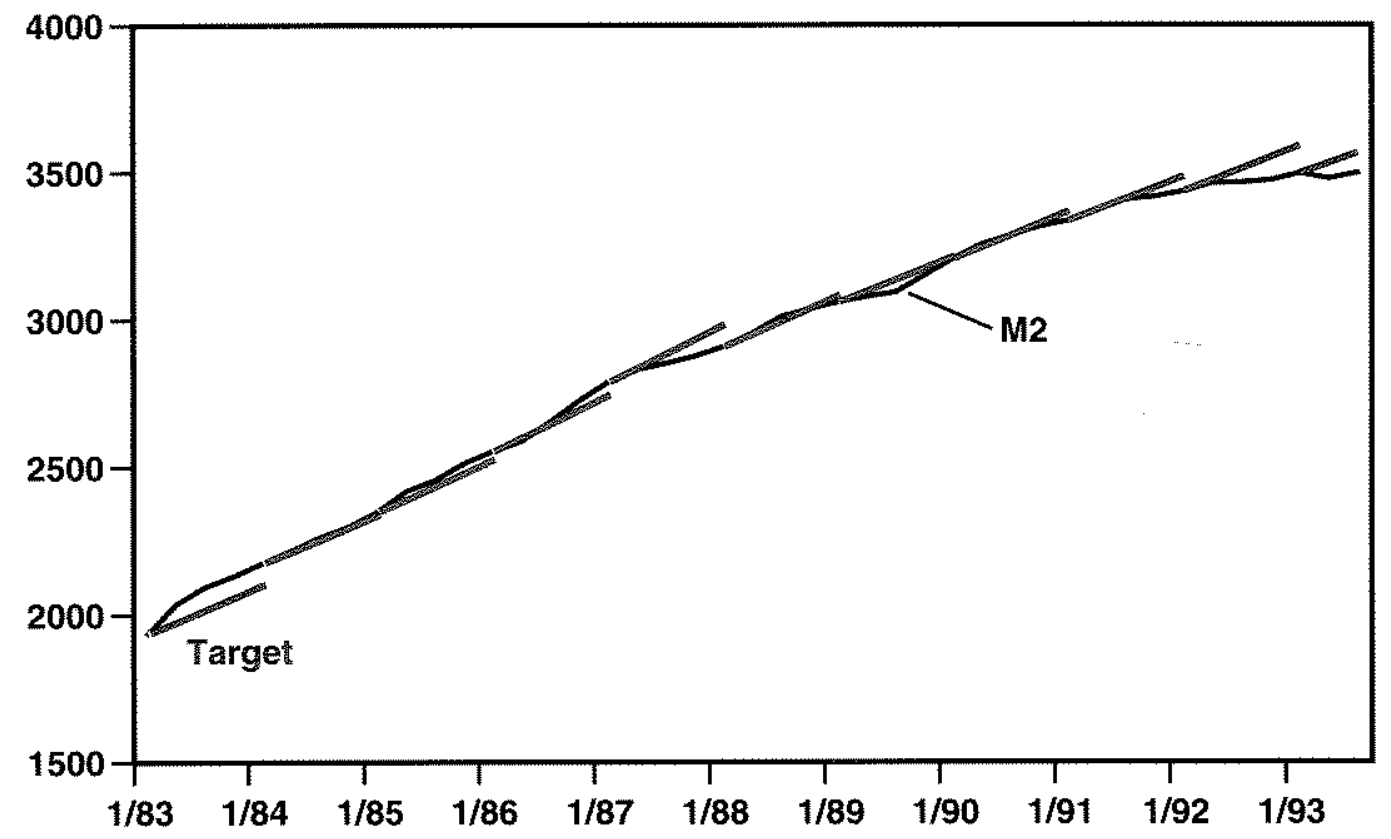

Figure 11

Quarterly Growth in M2/Base Ratio and Growth

Forecasted by a Time-Varying Coefficient Model

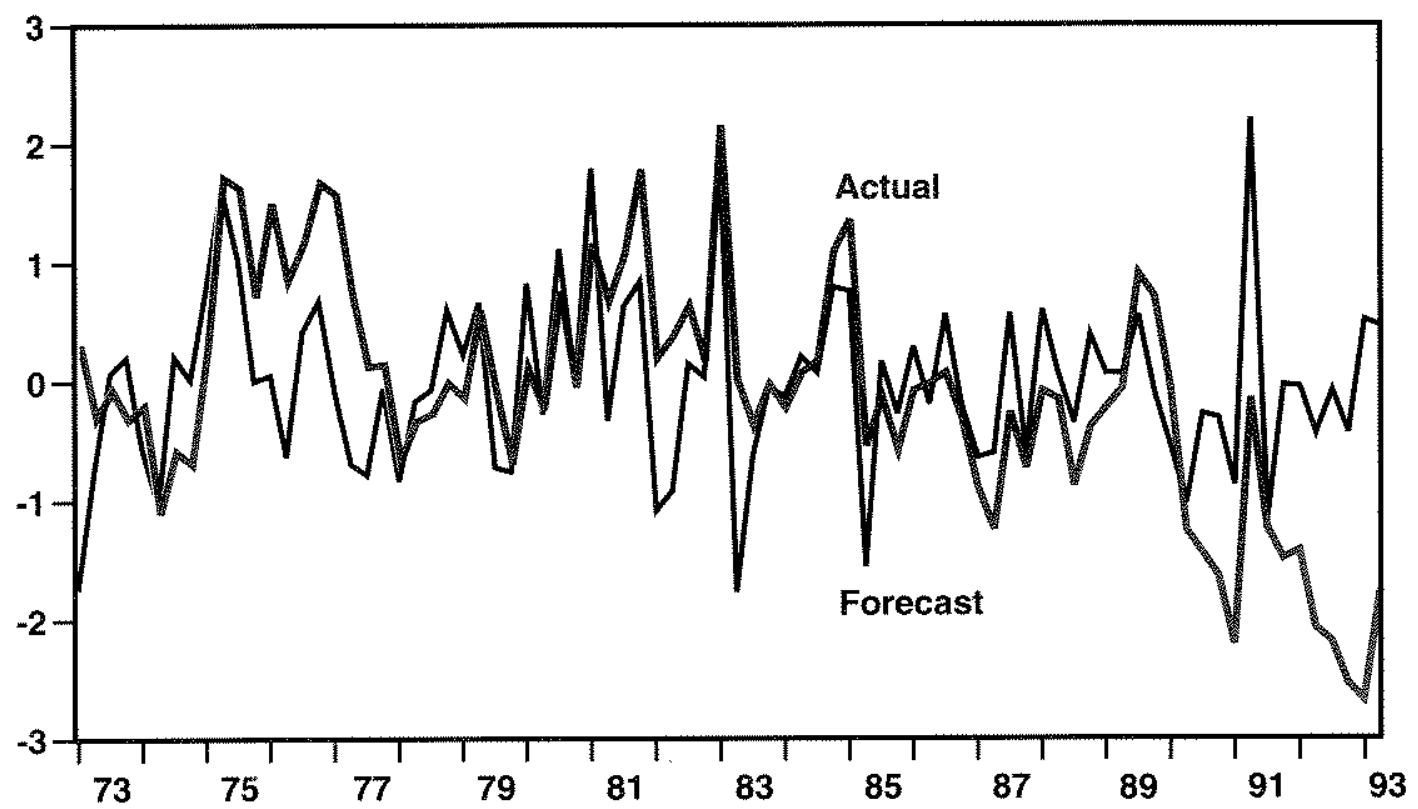


Figure 12

\section{Quarterly Growth in M2 Velocity and Forecasted Growth from a Time-Varying Coefficient Model}

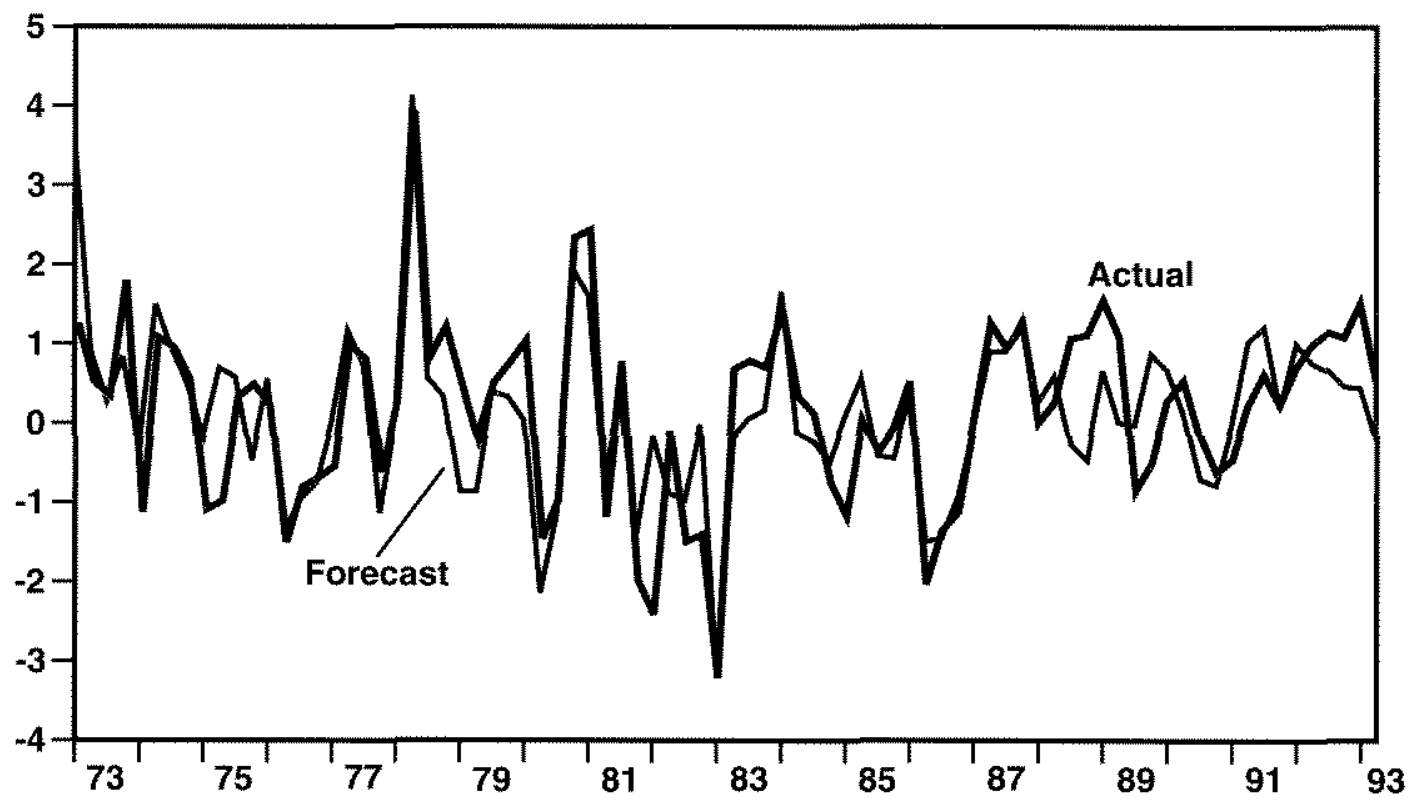

down in the relationship between $\mathrm{M} 2$ and narrower aggregates, like the monetary base, is more pronounced than the much-discussed breakdown in $\mathrm{M} 2$ velocity. A comparison of recent forecast errors in the growth of the $\mathrm{M} 2 /$ base ratio (figure 11) and growth in M2 velocity (figure 12) shows that the $\mathrm{M} 2 /$ base ratio has suffered larger forecast errors than M2 ve. locity. For example, in the first quarter of 1993, the forecasting model overpredicted growth in the M2/base ratio by more than 3 percentage points for the quarter. The corresponding forecast error for growth in base velocity never approaches such a size. Apart from their relative magnitudes, errors in forecasting the $\mathrm{M} 2 /$ base ratio and M2 velocity, when combined, help explain the FOMC's decision to de-emphasize M2 as a guide to monetary policy in July 1993. First, in the current financial environment, it is difficult to predict with precision the rate of base growth needed to put M2 at the midpoint of its target range. It is also difficult to predict precisely the rate of nominal GDP growth that will accompany a given rate of M2 growth. Viewed this way, M2 has diminished value as an intermediate policy target.

As a summary, table 2 contains measures of the bias and mean-squared error between actual and model-implied base growth, both in- and out-of-sample, for the TVC M2 and MA M2 models as percents of the corresponding measures for the rebased target GDP model. The models of M2 targeting have in-sample (1983-90), mean-squared errors that are more than an order of magnitude larger than that for the rebased target GDP model. In the out-of-sample, post-1990 period, however, the models of M2 targeting actually have lower mean-squared errors than all three GDP targeting models. Nevertheless, as discussed above, the breakdown in forecasting models of the $\mathrm{M} 2 /$ base ratio prevents the $\mathrm{M} 2$ targeting models from providing reliable monetary policy indicators in the 1990s.

\section{SUMMARY}

This article studies the policy prescriptions embedded in feedback rules as monetary policy indicators. The selected feedback rules give a large role to forecasts, so recent difficulties in forecasting the relationships between various monetary aggregates and the level of nominal spending have been emphasized. The results from M2 targeting models suggest that M2 has recently lost many of the properties-specifically, predictable relationships with narrow 
Table 2

Model Comparison

\begin{tabular}{|c|c|c|c|c|}
\hline \multirow[b]{2}{*}{ Mode } & \multicolumn{2}{|c|}{$1983-1990$} & \multicolumn{2}{|c|}{1990.1993} \\
\hline & Meen-Squared Eror & Blas & Woansquared E =1ror & Blas \\
\hline $\begin{array}{l}\text { Rebased Targef Gop } \\
\text { We he } \\
\text { MA h2 }\end{array}$ & $\begin{array}{l}100 \% 6 \\
2,3940 \% \\
2,3910 \%\end{array}$ & $\begin{array}{r}100 \%(r) \\
2,7590 \%(>0) \\
4,236 \%)(>0)\end{array}$ & $\begin{array}{r}100 \% \% \\
5 \\
5 \% \%\end{array}$ & 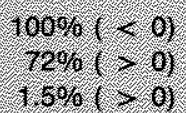 \\
\hline
\end{tabular}

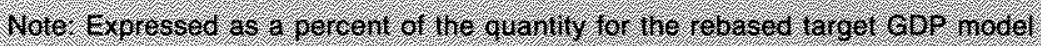

monetary policy instruments and stable velocitythat had made it an attractive intermediate target. Furthermore, growth in the monetary base has been consistent with growth implied by models of M2 targeting in the 1990s. The shortcomings in M2 growth appear to stem from shortfalls in the M2/base ratio, relative to predicted levels.

Among models of nominal GDP targeting, the model that gradually adjusts the target path of nominal GDP for past deviations from a desired 5.7 percent annual rate of nominal GDP growth best explains base growth in terms of minimizing mean-squared error between 1983 and 1990. Furthermore, no persistent divergence has appeared in the post-1990, out-of-sample period between actual nominal GDP and the level implied by the rebased target GDP model. Nevertheless, it is too early to tell whether monetary policy will remain as consistent with that implied by the rebased target model as it was in the $1980 \mathrm{~s}$.

One attractive feature of the models of nominal GDP targeting is that they provide an estimate of the desired long-run rate of nominal GDP growth. From this rate, it is straightforward to calculate an approximate long-run inflation objective by subtracting an estimate of the rate of growth of potential real GDP. The resulting estimate of the implicit long-run inflation objective should be as credible as the assumptions behind the policy model. Furthermore, because one of the assumptions is that the Fed's longrun inflation objective remains constant, one can use the nominal GDP targeting models to search for possible shifts in that objective.

\section{REFERENGES}

Bomhoff, Eduard. "Predicting the income Velocity of Money: A Kalman Filter Approach," unpublished manuscript, Erasmus University (Netherlands: June 1991).

Bradley, Michael D, and Dennis W. Jansen. "Understanding Nominal GNP Targeting," this Review (November/December 1989), pp. $31-40$.

Dueker, Michael. "Can Nominal GDP Targeting Rules Stabilize the Economy?" this Review (May/June 1993), pp. 15-29.

Engle, Robert F. "Autoregressive Conditional Heteroscedasticity with Estimates of the Variance of United Kingdom Inflation," Econometrica (July 1982), pp. 987-1007.

, and Mark Watson. "Kalman Filter: Applications to Forecasting and Rational Expectations Models;" Advances in Econometrics, Fifth World Congress (Vol. 1, 1985), pp. $245-81$.

Feldstein, Martin, and James H. Stock. "The Use of Monetary Aggregate to Target Nominal GDP,' NBER Working Paper No. 4304 (March 1993).

Friedman, Milton, and Anna J. Schwarz. A Monetary History of the United States, 1867-1960 (Princeton University Press, 1963).

Hallman, Jeffrey J., Richard D. Porter and David H. Small. "is the Price Level Tied to the M2 Aggregate in the Long Run?"' American Economic Review (September 1991), pp. $841-58$.

Hein, Scott E., and Paul T.W.M. Veugelers. "Predicting VelociIy Growth: A Time Series Perspective," this Review (Oc. tober 1983), pp. 34-43.

Kim, Chang-Jin. "Dynamic Linear Models with MarkovSwitching:" Joumal of Econometrics (January/February 1994), pp. 1-22.

"Sources of Monelary Growth Uncertainty and Economic Activity: The Time-Varying Parameter Model with Heteroscedastic Disfurbances:" The Review of Economics and Statistics (forthcoming).

McCallum, Bennett T. "The Case for Rules in the Conduct of Monetary Policy: A Concrete Example," Federal Reserve Bank of Richmond Economic Review (September/ October 1987), pp. 10-18.

"Robustness Properties of a Rule for Monetary Policy," Camegie-Rochester Conference Series on Public Policy 29 (Autumn 1988), pp. 173-203. 

published manuscript (August 1993).

Motley, Brian, and John P. Judd. "An Alternative Strategy for Monetary Policy," Federal Reserve Bank of San Francisco Weekly Letter No. 93-01 (January 1, 1993).
Ritter, Joseph A. "The FOMC in 1992: A Monetary Conundrum" this Review (May/June 1993), pp. 31-49.

Romer, Christina D., and David H. Romer. "Does Monetary Policy Matter? A New Test in the Spirit of Friedman and Schwartz;" NBER Macroeconomics Annual (1989).

\section{Appendix The Time-Varying Coefficient Model}

Let $V$ stand for either the income velocity of the monetary base or the ratio between $\mathrm{M} 2$ and the base, TB3 for the three-month T-bill rate and $M B$ for the monetary base. The model generating the short-run forecasts is

$$
\begin{aligned}
& \Delta l n V_{t}=\beta_{0 t}+\beta_{I t} \Delta T B 3_{t-1}+\beta_{2 t} \Delta l n M B_{l \cdot 1}+e_{t} \\
& e_{i} \sim \text { Normal }\left(0, h_{\mathrm{r}}\right) \\
& \mathrm{h}_{t}=\mathrm{o}_{0}^{2}+\left(\sigma_{1}^{2}-\mathrm{o}_{0}^{2}\right) S_{\mathrm{t}} \\
& S_{t} \in\{0,1\} \\
& \sigma_{1}^{z}>\sigma_{0}^{2} \\
& \operatorname{Probability}\left(S_{\varepsilon}=1 \mid \mathrm{S}_{t-1}=1\right)=p \\
& \text { Probability }\left(S_{t}=o \mid \mathrm{S}_{t \cdot t}=0\right)=q \text {. }
\end{aligned}
$$

The errors in equation (A1), $e_{t^{\prime}}$ have timevarying volatilities in that their variance is assumed to switch between a low and high level according to a first-order Markov process. ${ }^{1}$

With time-varying coefficients, equation (A1) will be estimated using the Kalman filter under the assumption that the state variables, $\beta_{t}$, follow random walks: ${ }^{2}$

(A2) $\beta_{i}=\beta_{i-3}+v_{t}$

$$
v_{1} \sim \operatorname{Normal}(0, Q)
$$

In a short-run forecasting context, the assumption that the coefficients follow random walks suggests that people need new informa.

1The combination of time-varying parameters and this type of heteroscedasticity was introduced by $\mathrm{Kim}$ (forthcoming). $\mathrm{Kim}$ also ilustrates that this model of heteroscedasticity is quite similar in practice to the well-known autoregressive conditional heteroscedastic (ARCH) model of Engle (1982). Basically, the Markov model tries to match the persistence of periods of high and low volatility in the data, where persistence of high and low volatility states is increasing in $p$ and $q$, respectively. tion before changing their views about the relationships among variables. This is essentially why Engle and Watson (1985) advocate that time-varying coefficients should have unit roots. The innovations to the coefficients, $v$, are assumed to be uncorrelated, so the covariance matrix $\mathrm{Q}$ is diagonal. Kim (forthcoming) discusses the specific form the Kalman filtering takes for this model and the evaluation of the likelihood function, which is maximized with respect to

$\left(\sigma_{0}^{2}, \sigma_{i}^{2}, p, q, O\right)$, where $Q_{i i}=\sigma_{v i}^{2}, i=1,2,3$.

By construction, this model allows for two sources of forecast eггог: error in predicting the value of the coefficients and the heteroscedastic random disturbance. In general, in a model with time-varying coefficients,

(A3) $y_{t}=X_{t-1}^{\prime} \beta_{t}+e_{t} ;$

the one-step-ahead forecasts are

(A4) $y_{t / 1-1}=X_{t-1}^{\prime} \beta_{t / 2-1}$.

The forecast errors have two components which equal $X_{t-1}^{\prime}\left(\beta_{t}-\beta_{t t_{1}}\right)+e_{t^{\prime}}$ If the variance of $\left(\beta_{\mathrm{t}}-\beta_{t(t \cdot \mathrm{t})}\right) \equiv R_{t\} \cdot 1}$ and $\operatorname{var}\left(e_{\mathrm{r}}\right) \equiv \sigma_{\alpha^{\prime}}^{2}$ the one-stepahead, forecast-error variance is

$$
H_{t}=H_{I t}+H_{2 t}=X_{t-1}^{\prime} R_{t h 1} X_{t-1}+\sigma_{e}^{2}
$$

The first component $\left(H_{12}\right)$ is called the variance due to time-varying parameters (TVP); the second $\left(H_{23}\right)$ is simply the variance of the random

Bomhoff (1991) and Hein and veugelers (1983) also use the Kalman filter to forecast velocity. Bomhoff holds the interest elasticity $\left(\beta_{t}\right)$ consiant and restricts $\beta_{2}$ to equal zero, so past money growth is not included in his forecasts. Hein and Veugelers restrict both $\beta_{1 t}$ and $\beta_{2 t}$ to equal zero, further restricting the information set used for forecasting. 
disturbance $e$. Inferences about the relative sizes of the two sources of forecast error variance play an important role in updating the coefficients. One can write the forecast $y_{t+1 / t}$ as

(A6) $y_{t+1 / t}=X^{\prime} \beta_{t / t-s}+Z_{t} \eta_{t / t-z^{\prime}}$

where $X_{i}$ are the explanatory variables, $\eta_{t / 1}$ last period's forecast error (and therefore is the new information available), and $Z_{t}$ is proportional to

$$
\frac{H_{u t}}{H_{u t}+H_{2 t}}
$$

If $H_{2 t}$ is large relative to $H_{t t^{\prime}}$ observers would attribute less of a forecast error to a change in coefficients; instead, they would believe that it was probably an outlier. A large value of $H_{z t}$ then implies that last period's forecast error would play a relatively small role in determining next period's forecast. 